\title{
1 vRNA-vRNA interactions in influenza A virus HA vRNA
}

\section{2 packaging}

3

4 Sho Miyamoto ${ }^{1,2}$, Yukiko Muramoto ${ }^{1}$, Keiko Shindo ${ }^{1,3}$, Yoko Fujita ${ }^{1,4}$,

5 Takeshi Morikawa1,4, Ryoma Tamura ${ }^{1,4}$, Jamie L Gilmore ${ }^{1}$, Masahiro

$6 \quad$ Nakano ${ }^{1,4}$, Takeshi Noda ${ }^{1,4^{*}}$

7

81 Laboratory of Ultrastructural Virology, Institute for Frontier Life and

9 Medical Sciences, Kyoto University, Kyoto, Japan

102 Department of Molecular Virology, Graduate School of Medicine, Kyoto

11 University, Kyoto, Japan

$12{ }^{3}$ Keihanshin Consortium for Fostering the Next Generation of Global

13 Leaders in Research, Kyoto, Japan

$14{ }^{4}$ Laboratory of Ultrastructural Virology, Graduate School of Biostudies,

15 Kyoto University, Kyoto, Japan

16

$17{ }^{*}$ Corresponding author 
bioRxiv preprint doi: https://doi.org/10.1101/2020.01.15.907295; this version posted January $16,2020$. The copyright holder for this preprint (which was not certified by peer review) is the author/funder, who has granted bioRxiv a license to display the preprint in perpetuity. It is made available under aCC-BY-NC-ND 4.0 International license.

18 E-mail: t-noda@infront.kyoto-u.ac.jp (TN)

19 


\section{Abstract}

21 The genome of the influenza A virus is composed of eight single-stranded

22 negative-sense RNA segments (vRNAs). The eight different vRNAs are

23 selectively packaged into progeny virions. This process likely involves

24 specific interactions among vRNAs via segment-specific packaging signals

25 located in the $3^{\prime}$ and $5^{\prime}$ terminal coding regions of vRNAs. To identify

26 vRNA(s) that interact with hemagglutinin (HA) vRNA during genome

27 packaging, we generated a mutant virus, HA $5 \mathrm{~m} 2$, which possessed five

28 silent mutations in the 5' packaging signal region of HA vRNA. The HA 5m2

29 virus had a specific defect in HA vRNA incorporation, which reduced the

30 viral replication efficiency. After serial passaging in cells, the virus acquired

31 additional mutations in the 5' terminal packaging signal regions of both $\mathrm{HA}$

32 and PB2 vRNAs. These mutations contributed to recovery of viral growth

33 and packaging efficiency of HA vRNA. A direct RNA-RNA interaction

34 between the $5^{\prime}$ ends of HA and PB2 vRNAs was confirmed in vitro. Our

35 results indicate that direct interactions of HA vRNA with PB2 VRNA via their

36 packaging signal regions are important for selective genome packaging and 
bioRxiv preprint doi: https://doi.org/10.1101/2020.01.15.907295; this version posted January $16,2020$. The copyright holder for this preprint (which was not certified by peer review) is the author/funder, who has granted bioRxiv a license to display the preprint in perpetuity. It is made available under aCC-BY-NC-ND 4.0 International license.

37 enhance our knowledge on the emergence of pandemic influenza viruses

38 through genetic reassortment. 


\section{Introduction}

The genome of the influenza A virus consists of eight segmented,

41 single-stranded, negative-sense viral RNAs (vRNAs). Each vRNA contains

42 a central coding region in an antisense orientation. This region is flanked

by segment-specific noncoding regions and common terminal promoter

44 sequences. Each vRNA forms a helical, rod-shaped ribonucleoprotein

45 complex (VRNP) that associates with multiple nucleoproteins (NPs) and with

a heterotrimeric RNA-dependent RNA polymerase complex composed of

47 PB2, PB1, and PA proteins. The VRNP is responsible for transcription and

replication of constituent vRNA. Recent studies examining NP-vRNA

interactions in the context of vRNPs have shown that the NPs bind to VRNA

nucleotides non-uniformly without sequence specificity[1,2], suggesting

51 that some parts of the vRNAs are free of NPs, and can potentially form

secondary or tertiary structures that protrude from the surface of rod-

shaped vRNPs.

There is evidence to suggest that progeny virions selectively 
are arranged in a specific ' $1+7$ ' pattern, where one vRNP is surrounded by

57 the other seven vRNPs[3,4]. The mechanism by which each copy of the

58 eight vRNAs is selected from a large pool of vRNAs and non-viral RNAs in

59 virus-infected cells, and how these vRNAs are organized into the specific

60 ' $1+7$ ' arrangement, remains unclear. The segment-specific packaging signal

61 sequences, located in the noncoding and terminal coding regions of both

62 the $3^{\prime}$ and 5 ' ends of each VRNA, likely ensure the integrity of genome

63 packaging[5-10]. The terminal coding regions within these packaging signal

64 sequences are thought to be involved in co-packaging of multiple vRNAs,

65 and are referred to as bundling signals [11]. Mutations or deletions in

66 bundling signal sequences reduce the packaging efficiency of several

67 vRNAs. The impact of such mutations or deletions on packaging efficiency

68 is hierarchical among the eight vRNAs[8, 12-19], suggesting that there are specific interactions among the vRNPs. The vRNPs form sub-bundles en route to the plasma membrane $[20,21]$, and $v R N P s$ in virions are directly

71 or indirectly interconnected with each other[22, 23]; these findings offer

72 additional evidence for the existence of vRNA-vRNA interactions. 
To further examine the likely involvement of vRNA-vRNA

74 interactions in genome packaging, it is necessary to identify which vRNA

75 segments interact with one another, and which regions of each vRNA

76 segment participate in these interactions. The potential in-vitro interactions

77 of various naked vRNA segments have previously been described in human

$78 \mathrm{H} 3 \mathrm{~N} 2$ and avian H5N2 viruses $[22,24]$. However, the various combinations

79 of vRNA-vRNA interactions differ between the two viruses. It also remains

80 unclear whether such in-vitro vRNA-vRNA interactions in the absence of

81 NPs reflect interactions that may occur among vRNPs in vivo. Only some

82 nucleotides that are important for vRNA-vRNA interactions have been

83 identified in the context of virus replication in cells and co-packaging into

84 virions[22, 25]. These studies suggest that the 5' ends of M vRNA and the

85 central coding region of PB1 VRNA are involved in interactions and co-

86 packaging with NA VRNA, respectively. In addition, interactions between

87 PB1 and NS vRNAs may also be necessary for efficient viral replication and

88 genome packaging. However, the region in NS VRNA identified to interact

89 with PB1 VRNA is not located in the region of the previously reported 
genome packaging signal [26]. Thus, the role of vRNA-vRNA interactions in

91 genome packaging remains unclear.

92 In this study, we used serial passaging to identify which vRNA(s)

93 interact with the hemagglutinin (HA) vRNA packaging signal in selective

94 genome packaging. We first generated a mutant influenza virus (A/WSN/33)

95 that possesses five silent mutations in the packaging signal of HA vRNA,

96 which causes a specific defect in the incorporation of HA vRNA. Then, we

97 serially passaged the mutant virus in cultured cells to restore efficient

98 incorporation of HA vRNA, and identified mutations that had been newly

99 introduced into the vRNAs. In addition, we examined the interactions of HA

100 vRNA with potential partner vRNAs in vitro, and assessed the importance

101 of these vRNA-vRNA interactions in the packaging signal regions specific

102 for HA vRNA incorporation and viral replication. 
104 Results

105 Generation of mutant viruses possessing silent mutations in the 106 packaging signal of HA vRNA. potentially interacts with other vRNAs during selective genome packaging. For this, we used reverse genetics to generate a series of mutant viruses that possessed five silent mutations in either the $3^{\prime}$ or $5^{\prime}$ packaging signal

111 region of $\mathrm{HA}$ VRNA without any amino acid mutations (Fig 1A). The

112 respective viral titers were examined by plaque assays (Fig 1B). Eight out

113 of nine mutant viruses replicated at a level similar to that of the wild-type

114 virus, showing titers of approximately $3.8 \times 10^{8} \mathrm{PFU} / \mathrm{ml}$; however, an HA $5 \mathrm{~m} 2$ 115 virus, possessing five silent mutations at nucleotides 1664 to 1676 in HA 116 vRNA, exhibited an approximately $87 \%$ reduced growth rate compared to 117 the wild-type virus. Sequence analysis confirmed that no unexpected 118 mutations occurred in any of the eight vRNAs of the HA $5 \mathrm{~m} 2$ virus. These 119 results indicate that nucleotides 1664 to 1674 in the packaging signal region of HA vRNA are necessary for efficient virus growth and are likely involved 
121 in HA vRNA packaging, which in agreement with results reported by a

122 previous study[14].

123

124 Serial passaging of the HA $5 \mathrm{~m} 2$ virus in cells

125

We hypothesized that after several passages, the HA $5 \mathrm{~m} 2$ virus

126 would acquire adaptive mutations in vRNAs, which would restore viral

127 fitness. Accordingly, the HA $5 \mathrm{~m} 2$ virus was serially passaged in Madin-

128 Darby Canine Kidney (MDCK) cells, and viral titers were assessed by

129 plaque assay after each passage. The viruses were designated as HA $5 \mathrm{~m} 2$

$130 \mathrm{P} 1, \mathrm{P} 2, \mathrm{P} 3, \mathrm{P} 4, \mathrm{P} 5, \mathrm{P} 6, \mathrm{P} 7, \mathrm{P} 8, \mathrm{P} 9$, and $\mathrm{P} 10$ viruses, according to the

131 number of passages in MDCK cells. As expected, the growth of the HA $5 \mathrm{~m} 2$

132 P10 virus was restored to approximately $61 \%$ of that shown by the wild-type

133 virus (Fig 2A). The titer of the HA $5 \mathrm{~m} 2 \mathrm{P} 10$ virus did not increase with an

134 additional 10 passages (data not shown). Sequencing analysis of all eight

135 HA 5m2 P10 virus vRNAs revealed that two mutations were newly

136 introduced into the 5' terminal coding regions of HA vRNA (T1665C) and

137 PB2 vRNA (G2271T); both of these vRNAs are located within the previously 
identified genome packaging signaling regions $[6,8,14,16]$.

140 the HA $5 \mathrm{~m} 2$ virus, we used reverse genetics to generate recombinant $\mathrm{HA}$

$1415 \mathrm{~m} 2$ viruses with additional mutation(s). Recombinant HA $5 \mathrm{~m} 2$ viruses,

142 which possessed a single mutation in HA T1665C or PB2 G2271T, both

143 showed replication that was partially restored to 11 and $24 \%$ of the wild-

144 type virus, respectively (Fig 2B). The recombinant HA $5 \mathrm{~m} 2$ virus with a

145 double mutation showed replication that was approximately $65 \%$ of the wild-

146 type virus, similar to the replication levels of the HA 5m2 P10 virus (Fig 2A

147 and $2 \mathrm{~B})$.

substitutions HA S545P and PB2 Q748H, respectively. The amino acid 545

150 is located in the transmembrane region of the HA protein; hence, this

151 substitution may affect intracellular transport to the plasma membrane and

152 subsequent incorporation of HA proteins into progeny virions. Therefore, we

153 examined the amount of HA protein incorporated into progeny virions.

154 Western blotting showed that the amounts of HA protein were comparable 
in the HA 5m2 P10, HA $5 \mathrm{~m} 2 \mathrm{P} 1$, and wild-type virions. This suggests that

156 the S545P substitution has little or no effect on the amount of HA protein

157 incorporated into virions (Fig 2C). To examine the impact of the $\mathrm{Q} 748 \mathrm{H}$

158 substitution on the polymerase activity of the PB2 protein, we used RT-

159 qPCR to quantify the amount of VRNA in virus-infected cells at 7 hours post-

160 infection. The amount of vRNA was similar in HA 5m2 P10-infected, HA 5m2

161 P1-infected, and wild-type virus-infected cells, suggesting that the Q748H

162 substitution in PB2 had little or no effect on polymerase activity (Fig 2D).

163 Taken together, these results suggest that T1665C mutations in HA vRNA

164 and G2271T mutations in PB2 VRNA participate in the restoration of HA 5m2

165 viral replication at the RNA level.

166

167 Efficiency of packaging eight vRNAs in HA 5m2 viruses Because the HA $5 \mathrm{~m} 2$ virus possessed five silent mutations in the 5' packaging signal region of HA vRNA, we predicted that it would show defects in the packaging efficiency of vRNAs (especially of HA vRNA). We 
and PB2 vRNAs would improve the packaging efficiency of HA vRNA. To

173 assess the packaging efficiency of the HA $5 \mathrm{~m} 2 \mathrm{P} 1$ and HA $5 \mathrm{~m} 2 \mathrm{P} 10$ viruses,

174 we extracted vRNA from wild-type, HA 5m2 P1, and HA 5m2 P10 viruses;

175 then, we quantified the amount of the eight influenza vRNA segments using

176 RT-qPCR. As expected, the HA 5m2 P1 virus showed a marked defect in

177 the packaging efficiency of HA vRNA; the packaging efficiency was reduced

178 to approximately $24 \%$ compared with that of the wild-type virus. The HA $5 \mathrm{~m} 2$

179 P1 virus also showed small defects in the packaging efficiency of PA, NP,

180

and NA vRNAs (Fig 3A). Importantly, in the HA 5m2 P10 virus, the packaging

181 efficiency of HA vRNA was largely recovered to approximately $72 \%$ of that

182 in the wild-type, and those of PA, NP, and NA vRNAs were also partially

183 recovered (Fig $3 \mathrm{~A})$.

184

To further examine the contribution of the PB2 G2271T and HA

185 T1665C mutations to vRNA packaging efficiency, we used RT-qPCR to

186 analyze the amount of packaged VRNA in recombinant HA $5 \mathrm{~m} 2$ viruses

187 possessing a single mutation or a double mutation. In both recombinant HA

$1885 \mathrm{~m} 2$ viruses with either a single PB2 G2271T or HA T1665C mutation, the 
packaging efficiency of HA vRNA was restored to approximately 33 and $59 \%$

to that of the wild-type virus, respectively (Fig 3B). In the recombinant HA

$1915 \mathrm{~m} 2$ virus possessing the double mutation, the packaging efficiency of HA

VRNA was largely restored to approximately $77 \%$ of that of the wild-type

virus (Fig 3B); this was consistent with the packaging efficiency of HA vRNA

194 in the HA 5m2 P10 virus. Taken together, these results show that disruption

195 of the 5' genome packaging signal in HA vRNA reduces the packaging

196 efficiency of HA vRNA. Our results also show that additional mutations in

197 the sequences of $5^{\prime}$ genome packaging signals of HA and PB2 vRNAs are

198 required for efficient HA vRNA packaging. This suggests that functional

199 interactions occur between HA and PB2 vRNAs via their 5' genome

200 packaging signals during viral replication.

201

202 Ultrastructural analysis of the HA $5 \mathrm{~m} 2$ viruses.

204 HA 5m2 P10 viruses, we examined ultrathin sections via electron

205 microscopy (EM). Representative images of transversely and longitudinally 
bioRxiv preprint doi: https://doi.org/10.1101/2020.01.15.907295; this version posted January 16,2020 . The copyright holder for this preprint (which was not certified by peer review) is the author/funder, who has granted bioRxiv a license to display the preprint in perpetuity. It is made available under aCC-BY-NC-ND 4.0 International license.

sectioned wild-type, HA 5m2 P1, and HA 5m2 P10 virions, budding from the

207 cell surfaces, are shown in Fig 4A. While some transversely sectioned wild-

208 type and HA 5m2 P10 virions appeared empty, as reported previously [26],

209 almost all longitudinally sectioned wild-type and HA 5m2 P10 virions

210 contained RNPs positioned at the tip of the budding virions. Conversely, the

211 HA 5m2 P1 viruses often possessed empty particles in both transverse and

212 longitudinal sections, suggesting that the HA $5 \mathrm{~m} 2$ virus had defects in the

213 incorporation of RNPs.

214 To examine the incorporation of RNPs into virions in more detail,

215 we determined the proportion of empty particles in wild-type, HA $5 \mathrm{~m} 2 \mathrm{P} 1$,

216 and HA 5m2 P10 viruses. For this, virions were purified by

217 ultracentrifugation through a sucrose cushion and observed by cryo-TEM

218 (Fig 4B). The particles of the wild-type virus mainly showed uniformly

219 spherical shapes of approximately $111 \mathrm{~nm}$ in diameter; $0.9 \%(n=1085)$ of

220 virions appeared empty or contained only a few vRNPs (Table 1). With a

221 diameter of approximately $87 \mathrm{~nm}(\mathrm{n}=10, p<0.0001)$, such vRNP packaging-

222 deficient particles were significantly smaller than intact virions containing 
223 multiple RNPs. The proportion of vRNP packaging-deficient particles in the

224 HA 5 m2 P1 virus was $7.0 \%(n=1401)$, significantly higher than those of the

225 HA 5m2 P10 (3.2\%, n=852, $p<0.0001)$ and wild-type $(0.9 \%, n=1085$,

$226 p<0.0001)$ viruses. The results of EM analysis support the notion that

227 potential interactions between the 5' packaging signals of HA and PB2

228 vRNAs are important for appropriate genome packaging.

Table 1. Effect of silent mutations and passages on the packaging of RNPs into progeny virions

\begin{tabular}{ccccc} 
& $\begin{array}{c}\text { Experiment } \\
\text { no. }\end{array}$ & wt & $\begin{array}{c}\text { HA 5m2 } \\
\text { P1 }\end{array}$ & $\begin{array}{c}\text { HA 5m2 } \\
\text { P10 }\end{array}$ \\
\hline & 1 & $3 / 341$ & $32 / 505$ & $14 / 370$ \\
Proportion of & & $(0.9 \%)$ & $(6.3 \%)$ & $(3.7 \%)$ \\
vRNP packaging- & 2 & $7 / 744$ & $66 / 896$ & $13 / 482$ \\
deficient particles & & $(0.9 \%)$ & $(7.4 \%)$ & $(2.7 \%)$ \\
\cline { 2 - 5 } & Total & $10 / 1085$ & $98 / 1401$ & $27 / 852$ \\
& & $(0.9 \%)$ & $(7.0 \%)$ & $(3.2 \%)$ \\
$p$-value & & $<0.0001$ & & $<0.0001$
\end{tabular}

230 *Proportions of VRNP packaging-deficient particles in each virus were

231 compared with that in the HA $5 \mathrm{~m} 2 \mathrm{P} 1$ virus. Data were analyzed using

Dunnett's test. 
234 A direct interaction between HA and PB2 vRNA occurs via the 5 ' ends

235 of packaging signals in vitro

We next aimed to confirm that a functional interaction between the

237 5' terminal regions of HA and PB2 vRNAs is involved in efficient packaging

238 of HA vRNA. For this, we used a gel shift assay to examine whether direct

239 RNA-RNA interactions between these two vRNAs occur in vitro. To eliminate

240 possible nonspecific interactions via the non-packaging signal regions of

241 vRNAs, we synthesized a short HA vRNA comprising the 5' noncoding

242 region and the 120-nucleotide long coding region, which is designated as

243 5'HA(120). We also synthesized a short PB2 vRNA comprising the 5'

244 noncoding region and the 300-nucleotide long coding region, which is

245 designated as 5'PB2(300) (Fig 5A). In addition to the 5'HA(120) possessing

246 the wild-type HA vRNA sequence, we synthesized mutant 5'HA(120)

247 sequences into which we introduced five silent mutations corresponding to

248 HA 5m1, HA 5m2, HA 5m3, HA 5m4, and HA $5 \mathrm{~m} 5$ (Fig 1A); these mutant

249 5'HA(120) vRNAs were designated as 5'HA(120) 5m1, 5'HA(120) 5m2,

250 5'HA(120) 5m3, 5'HA(120) 5m4, and 5'HA(120) 5m5, respectively. The 
251 mixture of wild-type 5'HA(120) and 5'PB2(300) showed slower migration of

252 the band, indicating formation of a vRNA-vRNA complex (Figs 5B and 5C).

253 The mutant 5'HA(120) 5m1, 5'HA(120) 5m3, 5' $\mathrm{HA}(120) 5 \mathrm{~m} 4$, and 5' $\mathrm{HA}(120)$

$2545 \mathrm{~m} 5$ vRNAs also formed a complex with 5'PB2(300), whose proportions

255 were $69-95 \%$ compared to the complex of 5'HA(120) and 5'PB2(300). These

256 results are consistent with our viral replication data, showing that such

257 mutations in HA vRNA did not markedly affect viral growth (Fig 1B). In

258 contrast, the 5' $\mathrm{HA}(120) 5 \mathrm{~m} 2$ vRNA associated with 5'PB2(300) to a lesser

259 degree and did not form a vRNA-vRNA complex efficiently, with only $12 \%$

260 complex formation compared to the 5' $\mathrm{HA}(120)$ and 5'PB2(300), correlating

261 with the reduced viral growth of the HA $5 \mathrm{~m} 2$ virus (Fig 1B). Taken together,

262 these results indicate that there is an interaction between the 5 ' packaging

263 signals of HA and PB2 vRNAs in the context of vRNPs, which is important

264 for optimal packaging of HA vRNA. 
Discussion

267

Specific interactions among eight different vRNAs are likely

required for selective genome packaging of the influenza viruses. To identify

269 the interactions of HA vRNA in the context of RNPs, we generated a mutant

270 HA $5 \mathrm{~m} 2$ virus with reduced packaging efficiency of HA VRNA, and repeatedly

271 passaged this virus in cultured cells to restore viral fitness. We found that

272 the HA $5 \mathrm{~m} 2$ virus acquired additional mutations in the 5' packaging signal

273 sequences of HA and PB2 vRNAs; this restored HA vRNA packaging

274 efficiency and viral growth. Our results suggest that the packaging signal at

275 the $5^{\prime}$ terminal coding region of HA VRNA is involved in co-packaging of the

276 eight different vRNAs; this likely occurs via a direct RNA-RNA interaction

277 with the 5' packaging signal of PB2 vRNA. To the best of our knowledge,

278 this is the first study experimentally showing that a packaging-deficient

279 virus can recover its packaging efficiency by the introduction of mutations

280 in other vRNA segments during viral replication.

2821681 in HA vRNA, is more than $90 \%$ conserved in $\mathrm{H} 1$ subtype influenza 
bioRxiv preprint doi: https://doi.org/10.1101/2020.01.15.907295; this version posted January 16,2020 . The copyright holder for this preprint (which was not certified by peer review) is the author/funder, who has granted bioRxiv a license to display the preprint in perpetuity. It is made available under aCC-BY-NC-ND 4.0 International license.

283 viruses. However, the neighboring regions show less sequence

284 conservation [14], suggesting that this region is important for HA vRNA

285 packaging at the RNA level. Our results show that introduction of five silent

286 mutations into the highly conserved region at nucleotides 1664 to 1676 in

287 HA vRNA reduced the incorporation efficiency of HA vRNA (Fig. 2A). An

288 additional mutation at nucleotide 1665 restored the reduced efficiency of

289 HA vRNA packaging (Fig. 2B). This confirms that the highly conserved

290 region in the sequence of the 5 ' terminal packaging signal is involved in

291 incorporation of HA vRNA. Recent findings indicate that NP non-uniformly

292 decorates vRNA [1, 2]. Therefore, it is possible that the region at

293 nucleotides 1664 to 1676 in HA vRNA, identified in this study, is NP-free

294 and forms secondary or tertiary structures on vRNPs to interact with the 5'

295 packaging signal of PB2 vRNA. However, whether the 5 ' terminal coding

296 region of HA vRNA is a low NP-binding region remains unclear [1, 2].

297 Additional work is necessary to determine the precise location of the NP-

298 free region of HA vRNA in the A/WSN/33 strain.

After the HA $5 \mathrm{~m} 2$ virus was serially passaged in MDCK cells, the 
virus acquired a G2271T mutation in the 5' packaging signal sequence of

301 PB2 VRNA, which recovered the reduced incorporation of HA vRNA (Fig.

302 2B). This finding suggests that the region around nucleotide 2271 in PB2

303 vRNA is involved in interactions with HA vRNA. However, a previous study showed that the introduction of silent mutations at nucleotides 2268 to 2286 , including a mutation at nucleotide 2271, in PB2 vRNA did not reduce the packaging efficiency of HA vRNA [14]. Therefore, it is possible that the mutation at G2271T in PB2 vRNA, found in this study, was acquired for the optimal packaging of HA $5 \mathrm{~m} 2$ vRNA but not of wild-type HA vRNA.

311 of HA vRNAs at the nucleotide level [13]. In contrast, the 5' terminal coding

312 region of PB2 VRNA is highly conserved in influenza viruses [13, 17],

314 via their $5^{\prime}$ terminal regions may be specific to the H1 subtype. Native gel

315 electrophoresis analysis of in-vitro vRNA-vRNA interactions revealed that

316 avian $\mathrm{H} 5 \mathrm{~N} 2$ and human $\mathrm{H} 3 \mathrm{~N} 2$ viruses show different intersegmental 
317 networks among the eight vRNAs, and do not show strong interactions

318 between HA and PB2 vRNAs $[22,24]$. In the context of vRNPs, in-vitro

319 interactions do not necessarily reflect interactions in-vivo. Therefore,

320 further studies are needed to clarify whether HA vRNAs of other subtypes

321 require interactions with PB2 vRNA for HA vRNA packaging in the context

322 of vRNPs.

323

The reduced HA vRNA packaging efficiency of the HA $5 \mathrm{~m} 2$ virus was

324 rescued when the virus spontaneously acquired adaptive mutations in HA

325 and PB2 vRNAs during serial passaging (Fig. 2A and 2B). Previously, Marsh

326 et al., serially passaged an influenza A virus (WSN strain), which possesses

327 synonymous mutations in HA vRNAs, to determine whether the virus would

328 generate adaptive mutations for recovery of the reduced HA VRNA

329 packaging efficiency. However, the virus did not generate any mutations to

330 improve viral fitness [14]. This may have been due to the number of

331 synonymous mutations introduced into the HA vRNAs. Nine nucleotide

332 mutations were introduced into the region of 1659 to 1673 in the HA vRNAs

333 in the study by Marsh et al., while only five mutations were introduced into 
334 the region of 1664 to 1679 in HA vRNAs in our present study. More

335 mutations may cause severe incompatibility in VRNA-vRNA interactions.

336 Even repeated serial passaging may not generate multiple nucleotide

337 changes in HA vRNA and its respective interacting vRNA to restore the HA

338 vRNA packaging efficiency.

339

In conclusion, we have shown that an interaction between HA vRNA

340 and PB2 vRNA via the 5' packaging signals is important for HA vRNA

341 packaging. Our results suggest that HA vRNA is co-packaged with PB2

342 vRNA into virions. These findings will help us understand how reassortant

343 influenza viruses incorporate HA vRNA segments, and how pandemic

344 viruses emerge via genetic reassortment. 


\section{Materials and Methods}

\section{Cells}

349 Dulbecco's Modified Eagle Medium (D6046, Sigma) supplemented with 10\%

350 fetal bovine serum (FB-1365, Biosera, Chile). Madin-Darby Canine Kidney

351 (MDCK) cells were grown in Minimal Essential Medium (MEM)(11430-030,

352 Gibco) containing 5\% newborn calf serum (16010-159, Gibco, New Zealand).

353 Cultures were maintained at $37^{\circ} \mathrm{C}$ in a $5 \% \mathrm{CO}_{2}$ atmosphere. The medium

354 used during viral infection of cells was MEM containing $0.3 \%$ bovine serum

355 albumin (BSA/MEM).

356

357 Construction of the Poll HA plasmid 
364 contained cDNA sequences of the A/WSN/33(H1N1) viral genes; all

365 procedures were conducted as described previously [28]. Briefly, eight Poll

366 plasmids and pCAGGS protein-expression plasmids for PB2, PB1, PA, and

367 NP were mixed with the transfection reagent TransIT-293 (Mirus), and

368 added to $293 \mathrm{~T}$ cells cultured in BSA/MEM. At 48 hours post-transfection,

369 the cells were treated with $1 \mu \mathrm{g} / \mathrm{ml}$ of TPCK-Trypsin for $30 \mathrm{~min}$, centrifuged

370 at $1750 \times \mathrm{g}$ for $15 \mathrm{~min}$ at $4^{\circ} \mathrm{C}$, and the supernatant was harvested and stored

371 at $-80^{\circ} \mathrm{C}$. To generate mutant viruses, the Poll-HA wt plasmid was replaced

372 with a Poll-HA mutant plasmid. Viral titers were determined by a plaque

373 assay conducted using MDCK cells.

375 Virus purification

After collecting the supernatants from virus-infected MDCK cells,

377 each supernatant was clarified by centrifugation at $1750 \times \mathrm{g}$ for $15 \mathrm{~min}$ at

$3784^{\circ} \mathrm{C}$, followed by another centrifugation at $6700 \times \mathrm{g}$ for $30 \mathrm{~min}$ at $4^{\circ} \mathrm{C}$. To

379 eliminate RNAs outside of the virus particles, the supernatants were treated 
with $5 \mu \mathrm{g} / \mathrm{ml} \mathrm{RNase} \mathrm{A} \mathrm{(Nacalai} \mathrm{Tesque)} \mathrm{for} 1$ hour at $37^{\circ} \mathrm{C}$. Virions in the

\section{Western blotting} MDCK cells were infected with the viruses at a multiplicity of

387 infection (MOI) of 1 on ice for 1 hour. The infected MDCK cells were then

390 The purified virus was dissolved with an equal volume of $2 x$ Tris-Glycine

391 SDS Sample Buffer (Thermo Fisher Scientific) and boiled for 5 min without

392 a reducing agent, and then subjected to SDS-PAGE. Proteins were electroblotted onto Immobilon-P transfer membranes (Millipore

394 Corporation). The membranes were blocked with Blocking One (Nacalai

395 Tesque) for $30 \mathrm{~min}$ at room temperature, and then incubated with goat anti-

396 influenza A virus polyclonal antibody (ab20841, Abcam, 1:10,000 dilution) 
397 overnight at $4^{\circ} \mathrm{C}$. After incubation with rabbit anti-goat IgG secondary

398 antibody (ab6741, Abcam, 1:10,000 dilution) for 1 hour at room temperature,

399 the blots were developed using a Chemi-Lumi One Super (Nacalai Tesque).

400

401 RT-qPCR

402

The packaged vRNAs were extracted from purified viruses using an

403 RNeasy Mini Kit (Qiagen). 100 ng of extracted vRNAs were reverse

404 transcribed using a Uni-12 primer (5'-AGCRAAAGCAGG-3') and

405 Superscript III reverse transcriptase (Invitrogen). Quantification was

406 performed by qPCR on a Rotor-Gene Q 2plex System (Qiagen) using

407 segment-specific primers modified from the protocol by Marsh et al. The

408 primers used are listed in S1 Table. For each sample, reactions contained

$4091 \mu \mathrm{l}$ 10-fold diluted RT product, $7.5 \mu \mathrm{l}$ THUNDERBIRD SYBR qPCR Mix

410 (Toyobo), $0.25 \mu \mathrm{M}$ segment-specific primers, for a final volume of $15 \mu \mathrm{l}$.

411 Cycling conditions were: 2 min at $94^{\circ} \mathrm{C}$, followed by 40 cycles $\left(98^{\circ} \mathrm{C}\right.$ for 10

$412 \mathrm{~s}, 55^{\circ} \mathrm{C}$ for $15 \mathrm{~s}$, and $72^{\circ} \mathrm{C}$ for $\left.30 \mathrm{~s}\right)$.

In Figure 2D, total RNA was extracted from virus-infected cells 
414 using an RNeasy Mini Kit (Qiagen). For PB2, PB1, HA, and NP vRNAs, RT-

415 qPCR was performed as described above, using $100 \mathrm{ng}$ total RNA. The

416 values were expressed as numbers of RNA copies in an infected cell,

417 assuming that a cell contained $10 \mathrm{pg}$ of RNA [29, 30].

418

419 Ultrathin section electron microscopy (EM)

420

Ultrathin section EM was performed as described previously [3].

421 MDCK cells were infected at MOI=10. At 10 hours post-infection, the

422 infected cells were prefixed with $2.5 \%$ glutaraldehyde in $0.1 \mathrm{M}$ cacodylate

423 buffer ( $\mathrm{pH} 7.4)$ on ice. Ultrathin (50-nm-thick) sections were stained with $2 \%$

424 uranyl acetate in $70 \%$ ethanol and in Reynold's lead citrate. Representative

425 images were acquired using HT7700 (Hitachi).

427 Quantification of vRNP packaging-deficient particles

Purified viruses were applied onto C-flat holey carbon grids

429 (Protichips), which were blotted on a Vitrobot Mark IV (Thermo Fisher

430 Scientific) before plunge-freezing in liquid ethane. Samples were kept cool 
431 in liquid nitrogen. Samples were imaged at $200 \mathrm{kV}$ on a Talos F200C

432 (Thermo Fisher Scientific) equipped with a Ceta 16M CMOS camera (Gatan).

433 More than 300 particles were observed for each experiment.

434

435 In vitro RNA synthesis

436 Shortened HA and PB2 vRNAs were synthesized in vitro using T7

437 transcription as described previously [30]. Briefly, templates containing a

438 T7 phage promoter sequence (5'-TAATACGACTCACTATAGGG-3') were

439 amplified by PCR using corresponding primer pairs and were purified with

440 a QIAquick PCR purification kit (Qiagen). The primers used are listed in S1

441 Table. Purified PCR products were transcribed in vitro using the RiboMAX

442 Large Scale RNA Production System-T7 (Promega) at $37^{\circ} \mathrm{C}$ for $4 \mathrm{~h}$, followed

443 by RQ1 DNase I (Promega) digestion of the DNA template at $37^{\circ} \mathrm{C}$ for 15

444 min. The transcript was purified with an RNeasy Mini Kit.

445

\section{RNA binding assay}

RNA-RNA interactions were analyzed by electrophoretic mobility 
448 shift assays essentially as described previously [24]. To facilitate RNA

449 folding, adjustments were made to the reaction buffer employed and

450 incubation time as described below [31]. Pairs of purified vRNAs (2 pmol of

451 each vRNA) were denatured for $10 \mathrm{~min}$ at $65^{\circ} \mathrm{C}$ in $5 \mu \mathrm{l}$ of ultrapure water

452 and cooled on ice. We then added $5 \mu \mathrm{l}$ of 2 -fold concentrated buffer (final

453 concentration: $50 \mathrm{mM} \mathrm{HEPES}, 50 \mathrm{mM} \mathrm{KCl}$, and $20 \mathrm{mM} \mathrm{MgCl}_{2}$ ) and incubated

454 the samples for 2 hours at $37^{\circ} \mathrm{C}$. Then, $2 \mu$ of loading buffer $[40 \%(\mathrm{v} / \mathrm{v})$

455 glycerol and $0.05 \%(\mathrm{w} / \mathrm{v})$ bromophenol blue] was added to the samples, and

456 the samples were analyzed using $1.0 \%$ agarose gels containing $0.01 \%(\mathrm{w} / \mathrm{v})$

457 ethidium bromide. Native gel electrophoresis of the RNA complexes was

458 performed at $4^{\circ} \mathrm{C}$ in a buffer containing $50 \mathrm{mM}$ Tris, $44.5 \mathrm{mM}$ borate, and

$4590.1 \mathrm{mM} \mathrm{MgCl} 2$. We then determined the RNA weight fraction (\%) of each

460 band in each lane. The percentage of intermolecular complex formation was

461 determined by dividing the weight fraction of a band by the sum of weight

462 fractions in the corresponding lane. 
466 vRNP packaging-deficient particles and the formation efficiencies of vRNA-

467 vRNA complexes were calculated using Dunnett's test. Diameters of virus

468 particles observed by EM were statistically analyzed using Welch's t-test. P

469 values of $<0.01$ were considered significant. 
bioRxiv preprint doi: https://doi.org/10.1101/2020.01.15.907295; this version posted January $16,2020$. The copyright holder for this preprint (which was not certified by peer review) is the author/funder, who has granted bioRxiv a license to display the preprint in perpetuity. It is made available under aCC-BY-NC-ND 4.0 International license.

\section{Acknowledgments}

472 We thank Connor Park for editing the manuscript.

473 


\section{References}

475 1. Williams GD, Townsend D, Wylie KM, Kim PJ, Amarasinghe GK,

476 Kutluay SB, et al. Nucleotide resolution mapping of influenza A virus

477 nucleoprotein-RNA interactions reveals RNA features required for

478 replication. Nature communications. 2018;9(1):465. Epub 2018/02/02. doi:

479 10.1038/s41467-018-02886-w. PubMed PMID: 29386621; PubMed Central

480 PMCID: PMCPMC5792457.

$4812 . \quad$ Lee N, Le Sage V, Nanni AV, Snyder DJ, Cooper VS, Lakdawala SS.

482 Genome-wide analysis of influenza viral RNA and nucleoprotein association.

483 Nucleic acids research. 2017;45(15):8968-77. doi: 10.1093/nar/gkx584.

484 3. Noda T, Sagara H, Yen A, Takada A, Kida H, Cheng RH, et al.

485 Architecture of ribonucleoprotein complexes in influenza A virus particles.

486 Nature. 2006;439(7075):490-2. Epub 2006/01/27. doi:

487 10.1038/nature04378. PubMed PMID: 16437116.

488 4. Chou YY, Vafabakhsh R, Doganay S, Gao Q, Ha T, Palese P. One 489 influenza virus particle packages eight unique viral RNAs as shown by FISH 490 analysis. Proceedings of the National Academy of Sciences of the United 
491 States of America. 2012;109(23):9101-6. Epub 2012/05/02. doi:

492 10.1073/pnas.1206069109. PubMed PMID: 22547828; PubMed Central

493 PMCID: PMCPMC3384215.

494 5. Fujii Y, Goto H, Watanabe T, Yoshida T, Kawaoka Y. Selective

495 incorporation of influenza virus RNA segments into virions. Proceedings of

496 the National Academy of Sciences of the United States of America.

497 2003;100(4):2002-7. Epub 2003/02/08. doi: 10.1073/pnas.0437772100.

498 PubMed PMID: 12574509; PubMed Central PMCID: PMCPMC149948.

499 6. Watanabe T, Watanabe S, Noda T, Fujii Y, Kawaoka Y. Exploitation

500 of nucleic acid packaging signals to generate a novel influenza virus-based

501 vector stably expressing two foreign genes. Journal of virology.

502 2003;77(19):10575-83. Epub 2003/09/13. PubMed PMID: 12970442;

503 PubMed Central PMCID: PMCPMC228515.

504 7. Fujii K, Fujii Y, Noda T, Muramoto Y, Watanabe T, Takada A, et al.

505 Importance of both the coding and the segment-specific noncoding regions

506 of the influenza A virus NS segment for its efficient incorporation into virions.

507 Journal of virology. 2005;79(6):3766-74. Epub 2005/02/26. doi: 
10.1128/jvi.79.6.3766-3774.2005. PubMed PMID: 15731270; PubMed

509 Central PMCID: PMCPMC1075679.

510 8. Muramoto Y, Takada A, Fujii K, Noda T, Iwatsuki-Horimoto K,

511 Watanabe $\mathrm{S}$, et al. Hierarchy among viral RNA (vRNA) segments in their

512 role in VRNA incorporation into influenza A virions. Journal of virology.

$5132006 ; 80(5): 2318-25$. Epub 2006/02/14. doi: 10.1128/jvi.80.5.2318-

514 2325.2006. PubMed PMID: 16474138; PubMed Central PMCID:

515 PMCPMC1395381.

516 9. Ozawa M, Fujii K, Muramoto Y, Yamada S, Yamayoshi S, Takada A,

517 et al. Contributions of two nuclear localization signals of influenza A virus

518 nucleoprotein to viral replication. Journal of virology. 2007;81(1):30-41.

519 Epub 2006/10/20. doi: 10.1128/jvi.01434-06. PubMed PMID: 17050598;

520 PubMed Central PMCID: PMCPMC1797272.

521 10. Ozawa M, Maeda J, Iwatsuki-Horimoto K, Watanabe S, Goto H,

522 Horimoto $\mathrm{T}$, et al. Nucleotide sequence requirements at the $5^{\prime}$ end of the

523 influenza A virus M RNA segment for efficient virus replication. Journal of

524 virology. 2009;83(7):3384-8. Epub 2009/01/23. doi: 10.1128/jvi.02513-08. 
525 PubMed PMID: 19158245; PubMed Central PMCID: PMCPMC2655591.

526 11. Goto H, Muramoto Y, Noda T, Kawaoka Y. The genome-packaging

527 signal of the influenza A virus genome comprises a genome incorporation

528 signal and a genome-bundling signal. Journal of virology.

529 2013;87(21):11316-22. Epub 2013/08/09. doi: 10.1128/jvi.01301-13.

530 PubMed PMID: 23926345; PubMed Central PMCID: PMCPMC3807325.

531 12. Liang $\mathrm{Y}$, Hong $\mathrm{Y}$, Parslow TG. cis-Acting packaging signals in the

532 influenza virus PB1, PB2, and PA genomic RNA segments. Journal of

533 virology. 2005;79(16):10348-55. Epub 2005/07/30. doi:

534 10.1128/jvi.79.16.10348-10355.2005. PubMed PMID: 16051827; PubMed

535 Central PMCID: PMCPMC1182667.

536 13. Gog JR, Afonso Edos S, Dalton RM, Leclercq I, Tiley L, Elton D, et

537 al. Codon conservation in the influenza A virus genome defines RNA

538 packaging signals. Nucleic acids research. 2007;35(6):1897-907. Epub

539 2007/03/03. doi: 10.1093/nar/gkm087. PubMed PMID: 17332012; PubMed

540 Central PMCID: PMCPMC1874621.

541 14. Marsh GA, Hatami R, Palese P. Specific residues of the influenza A 
542 virus hemagglutinin viral RNA are important for efficient packaging into

543 budding virions. Journal of virology. 2007;81(18):9727-36. Epub 2007/07/20.

544 doi: 10.1128/jvi.01144-07. PubMed PMID: 17634232; PubMed Central

545 PMCID: PMCPMC2045411.

546 15. Hutchinson EC, Curran MD, Read EK, Gog JR, Digard P. Mutational

547 analysis of cis-acting RNA signals in segment 7 of influenza A virus. Journal

548 of virology. 2008;82(23):11869-79. Epub 2008/09/26. doi:

549 10.1128/jvi.01634-08. PubMed PMID: 18815307; PubMed Central PMCID:

550 PMCPMC2583641.

551 16. Liang Y, Huang T, Ly H, Parslow TG, Liang Y. Mutational analyses

552 of packaging signals in influenza virus PA, PB1, and PB2 genomic RNA

553 segments. Journal of virology. 2008;82(1):229-36. Epub 2007/10/26. doi:

554 10.1128/jvi.01541-07. PubMed PMID: 17959657; PubMed Central PMCID:

555 PMCPMC2224372.

556 17. Marsh GA, Rabadan R, Levine AJ, Palese P. Highly conserved

557 regions of influenza a virus polymerase gene segments are critical for

558 efficient viral RNA packaging. Journal of virology. 2008;82(5):2295-304. 
559 Epub 2007/12/21. doi: 10.1128/jvi.02267-07. PubMed PMID: 18094182;

560 PubMed Central PMCID: PMCPMC2258914.

561 18. Hutchinson EC, Wise HM, Kudryavtseva K, Curran MD, Digard P.

562 Characterisation of influenza A viruses with mutations in segment 5

563 packaging signals. Vaccine. 2009;27(45):6270-5. Epub 2009/10/21. doi:

564 10.1016/j.vaccine.2009.05.053. PubMed PMID: 19840659; PubMed Central

565 PMCID: PMCPMC2771075.

566 19. Gao Q, Chou YY, Doganay S, Vafabakhsh R, Ha T, Palese P. The

567 influenza A virus PB2, PA, NP, and M segments play a pivotal role during

568 genome packaging. Journal of virology. 2012;86(13):7043-51. Epub

569 2012/04/26. doi: 10.1128/jvi.00662-12. PubMed PMID: 22532680; PubMed

570 Central PMCID: PMCPMC3416350.

571 20. Chou YY, Heaton NS, Gao Q, Palese P, Singer RH, Lionnet T.

572 Colocalization of different influenza viral RNA segments in the cytoplasm

573 before viral budding as shown by single-molecule sensitivity FISH analysis.

574 PLoS pathogens. 2013;9(5):e1003358. Epub 2013/05/15. doi:

575 10.1371/journal.ppat.1003358. PubMed PMID: 23671419; PubMed Central 
PMCID: PMCPMC3649991.

577 21. Lakdawala SS, Wu Y, Wawrzusin P, Kabat J, Broadbent AJ,

578 Lamirande EW, et al. Influenza a virus assembly intermediates fuse in the

579 cytoplasm. PLoS pathogens. 2014;10(3):e1003971. Epub 2014/03/08. doi:

580 10.1371/journal.ppat.1003971. PubMed PMID: 24603687; PubMed Central

581 PMCID: PMCPMC3946384.

582 22. Fournier E, Moules V, Essere B, Paillart JC, Sirbat JD, Isel C, et al.

583 A supramolecular assembly formed by influenza A virus genomic RNA

584 segments. Nucleic acids research. 2012;40(5):2197-209. Epub 2011/11/15.

585 doi: 10.1093/nar/gkr985. PubMed PMID: 22075989; PubMed Central

586 PMCID: PMCPMC3300030.

587 23. Noda T, Sugita Y, Aoyama K, Hirase A, Kawakami E, Miyazawa A,

588 et al. Three-dimensional analysis of ribonucleoprotein complexes in

589 influenza A virus. Nature communications. 2012;3:639. Epub 2012/01/26.

590 doi: 10.1038/ncomms1647. PubMed PMID: 22273677; PubMed Central

591 PMCID: PMCPMC3272569.

592 24. Gavazzi C, Isel C, Fournier E, Moules V, Cavalier A, Thomas D, et 
al. An in vitro network of intermolecular interactions between viral RNA

594 segments of an avian H5N2 influenza A virus: comparison with a human

595 H3N2 virus. Nucleic acids research. 2013;41(2):1241-54. Epub 2012/12/12.

596 doi: 10.1093/nar/gks1181. PubMed PMID: 23221636; PubMed Central

597 PMCID: PMCPMC3553942.

598 25. Gilbertson B, Zheng T, Gerber M, Printz-Schweigert A, Ong C,

599 Marquet R, et al. Influenza NA and PB1 Gene Segments Interact during the

600 Formation of Viral Progeny: Localization of the Binding Region within the

601 PB1 Gene. Viruses. 2016;8(8). Epub 2016/08/25. doi: 10.3390/v8080238.

602 PubMed PMID: 27556479; PubMed Central PMCID: PMCPMC4997600.

603 26. Gavazzi C, Yver M, Isel C, Smyth RP, Rosa-Calatrava M, Lina B, et

604 al. A functional sequence-specific interaction between influenza A virus

605 genomic RNA segments. Proceedings of the National Academy of Sciences

606 of the United States of America. 2013;110(41):16604-9. Epub 2013/09/27.

607 doi: 10.1073/pnas.1314419110. PubMed PMID: 24067651; PubMed Central

608 PMCID: PMCPMC3799358.

609 27. Ochman H, Gerber AS, Hartl DL. Genetic applications of an inverse 
610 polymerase chain reaction. Genetics. 1988;120(3):621-3. Epub 1988/11/01.

611 PubMed PMID: 2852134; PubMed Central PMCID: PMCPMC1203539.

612 28. Neumann G, Watanabe T, Ito H, Watanabe S, Goto H, Gao P, et al.

613 Generation of influenza A viruses entirely from cloned cDNAs. Proceedings

614 of the National Academy of Sciences of the United States of America.

615 1999;96(16):9345-50. Epub 1999/08/04. PubMed PMID: 10430945; PubMed

616 Central PMCID: PMCPMC17785.

617 29. Hatada E, Hasegawa M, Mukaigawa J, Shimizu K, Fukuda R.

618 Control of Influenza Virus Gene Expression: Quantitative Analysis of Each

619 Viral RNA Species in Infected Cells. The Journal of Biochemistry.

$620 \quad 1989 ; 105(4): 537-46$.

621 30. Kawakami E, Watanabe T, Fujii K, Goto H, Watanabe S, Noda T, et

622 al. Strand-specific real-time RT-PCR for distinguishing influenza vRNA,

623 cRNA, and mRNA. Journal of virological methods. 2011;173(1):1-6. Epub

624 2010/12/28. doi: 10.1016/j.jviromet.2010.12.014. PubMed PMID: 21185869;

625 PubMed Central PMCID: PMCPMC3049850.

626 31. Buchmueller KL, Weeks KM. Tris-borate is a poor counterion for 
bioRxiv preprint doi: https://doi.org/10.1101/2020.01.15.907295; this version posted January 16, 2020. The copyright holder for this preprint (which was not certified by peer review) is the author/funder, who has granted bioRxiv a license to display the preprint in perpetuity. It is made available under aCC-BY-NC-ND 4.0 International license.

627 RNA: a cautionary tale for RNA folding studies. Nucleic acids research.

628 2004;32(22):e184. Epub 2004/12/17. doi: 10.1093/nar/gnh182. PubMed

629 PMID: 15601995; PubMed Central PMCID: PMCPMC545480.

630 
$1775 \mathrm{nt}$

HA vRNA

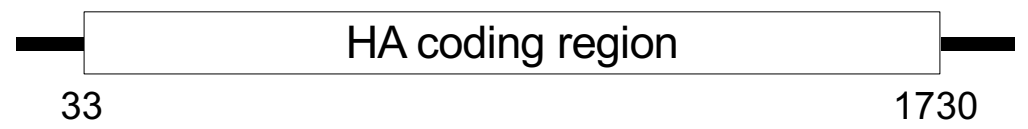

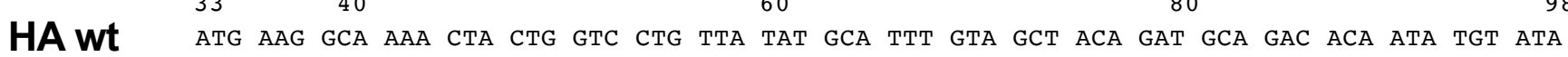
HA 3m1

HA 3m2

HA $3 m 3$

HA 3m4

HA wt

HA $5 \mathrm{~m} 1$

HA $5 \mathrm{~m} 2$

HA $5 \mathrm{~m} 3$

HA 5m4

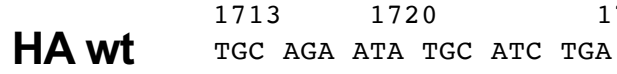

HA $5 m 5$.

B.

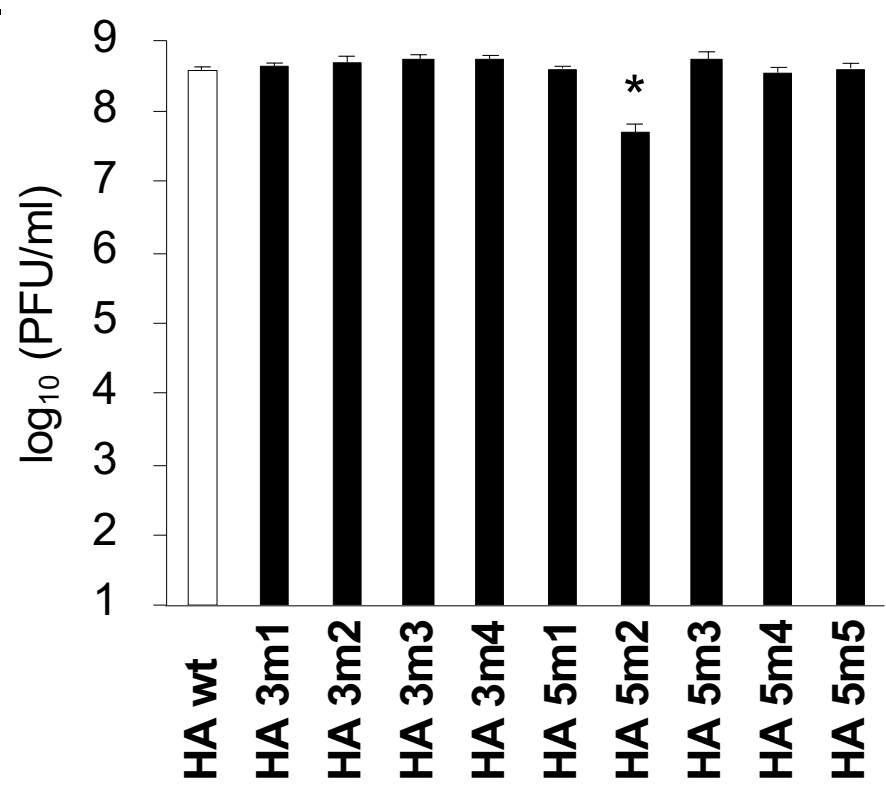

Fig 1. Generation of mutant influenza A viruses by reverse genetics and replication efficiencies of these mutant viruses. (A) Schematic diagram of mutant HA vRNAs with silent mutations introduced into the packaging signal sequences. The $3^{\prime}$ and $5^{\prime}$ ends of the HA coding region (nucleotides 33-98 and 1649-1730, respectively) are shown in the mRNA-sense orientation. (B) 293T cells were transfected with plasmids to produce the mutant and wild-type viruses. MDCK cells were infected with these mutant and wild-type viruses at a multiplicity of infection (MOI) of $10^{-5}$. Virus yields at $48 \mathrm{~h}$ post-infection were determined by a plaque assay on MDCK cells. The data represent the mean $\pm \operatorname{SD}(n=3)$. Dunnett's test; ${ }^{*} \mathrm{P}<0.01$ 
A.
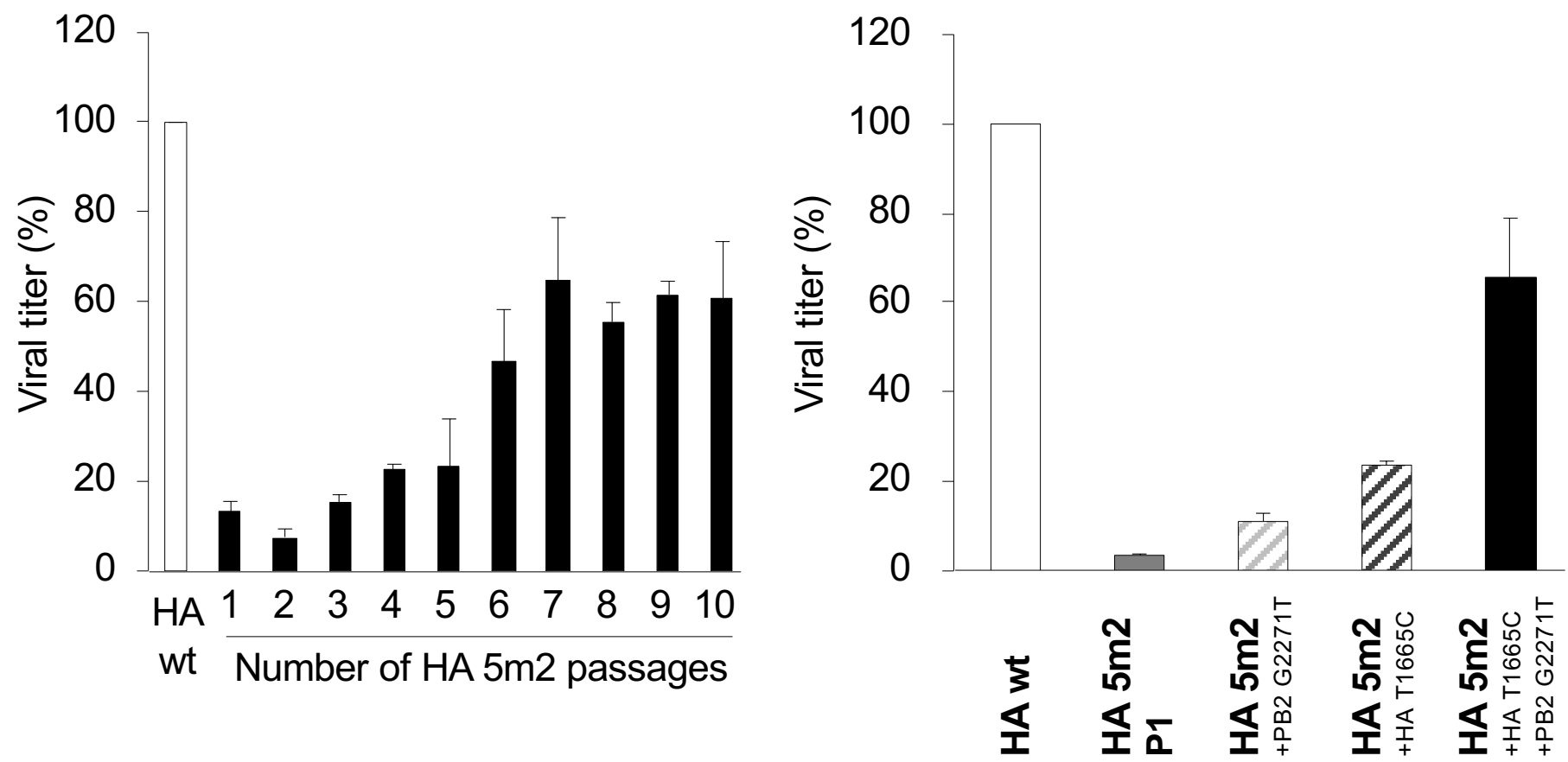

C.
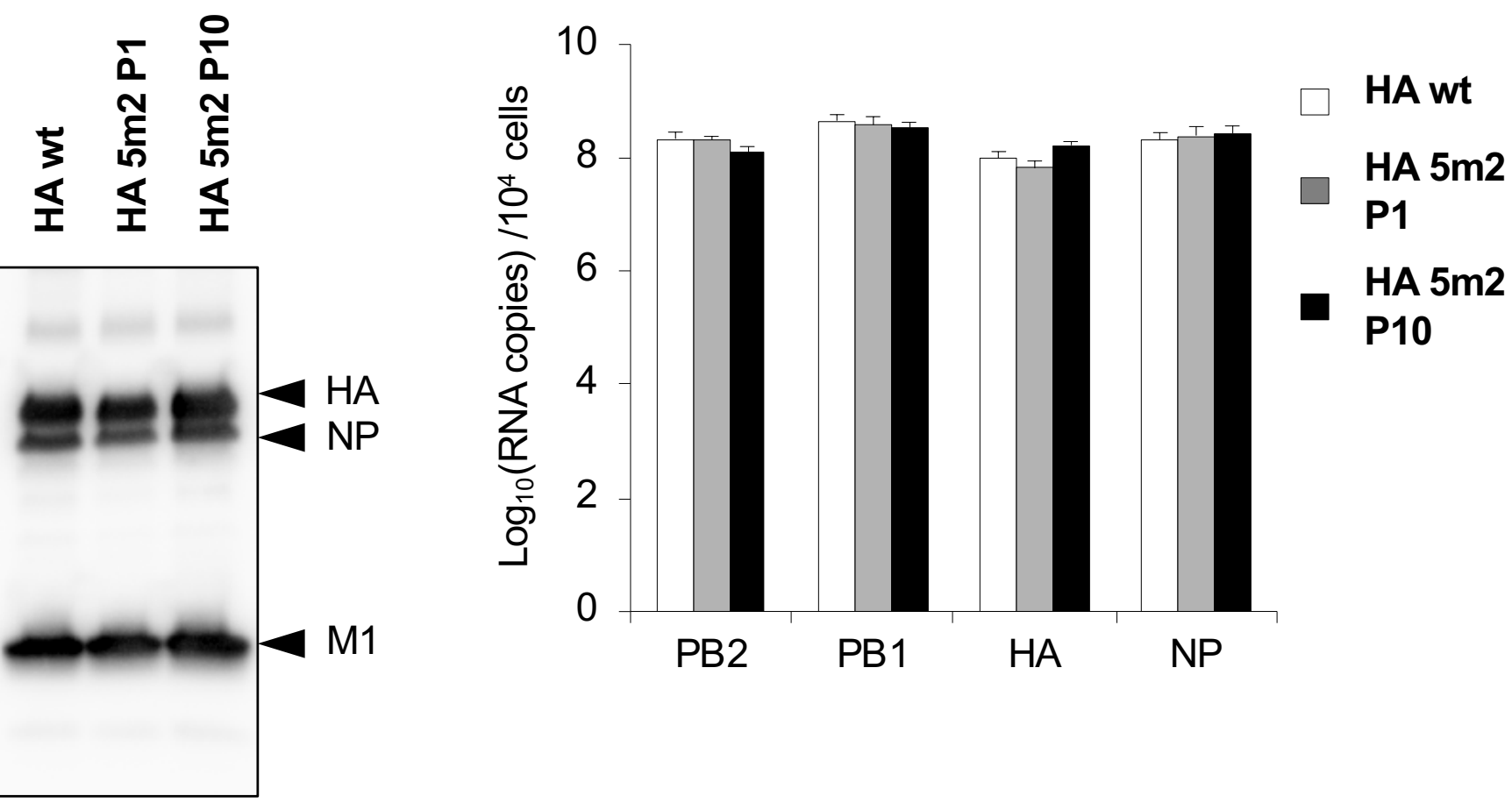

Fig 2. Analysis of HA $5 \mathrm{~m} 2$ viral replication. (A) The HA $5 \mathrm{~m} 2$ virus was passaged in MDCK cells at an $\mathrm{MOI}$ of $10^{-5}$. For each passage, supernatants were collected at 48 hours post-infection, and viral yields were determined by a plaque assay on MDCK cells. (B) 293T cells were transfected with plasmids to produce the mutant HA5m2 and wild-type viruses. After infecting MDCK cells at an $\mathrm{MOI}$ of $10^{-5}$, viral yields were determined at 48 hours postinfection. The data represent the mean $\pm S D(n=3)$. (C) The purified viruses were analyzed via western blot using an anti-influenza $A$ virus polyclonal antibody against $H A, N P$, and M1. (D) MDCK cells were infected with the viruses at an MOI of 1. Total RNA was extracted at 7 hours post-infection. PB2, PB1, HA, and NP vRNAs were analyzed using RTqPCR analysis. Data represent the mean $\pm S D$ of two independent experiments, each performed in triplicate. 


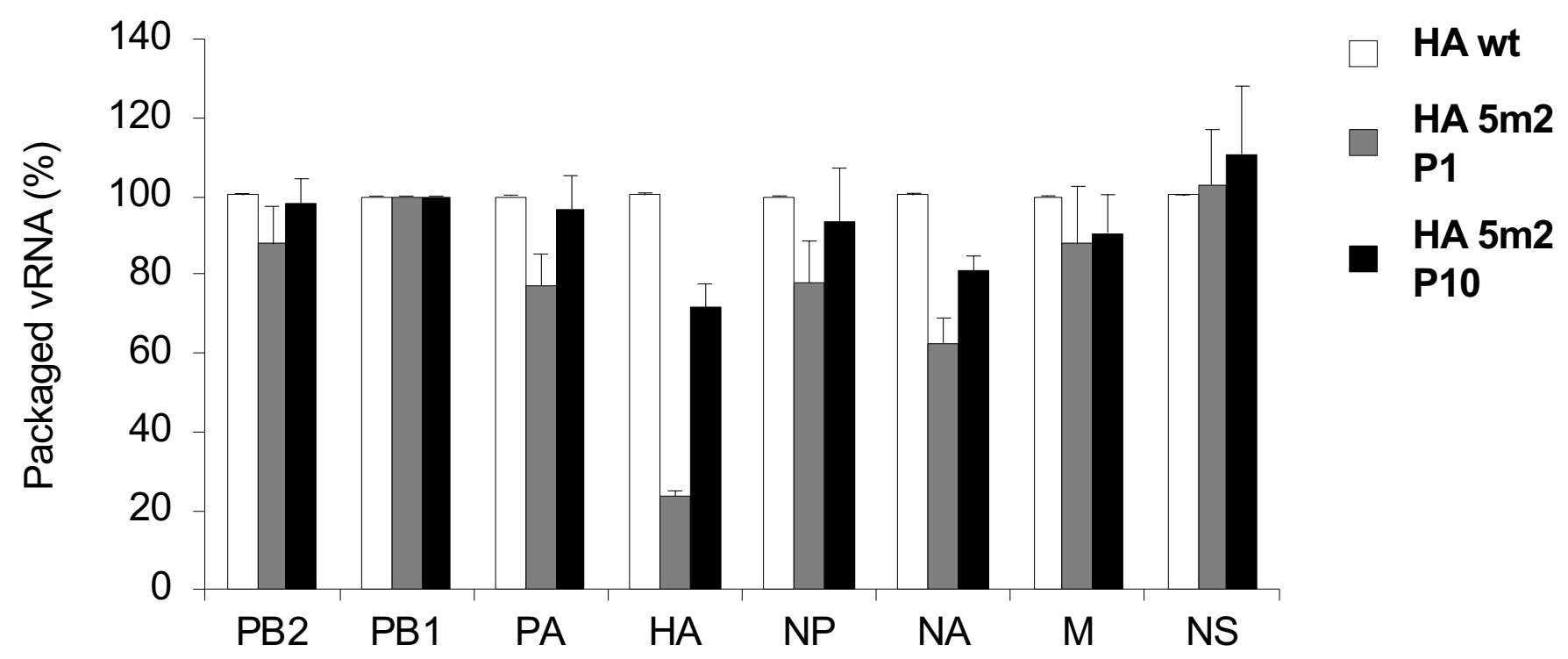

B.

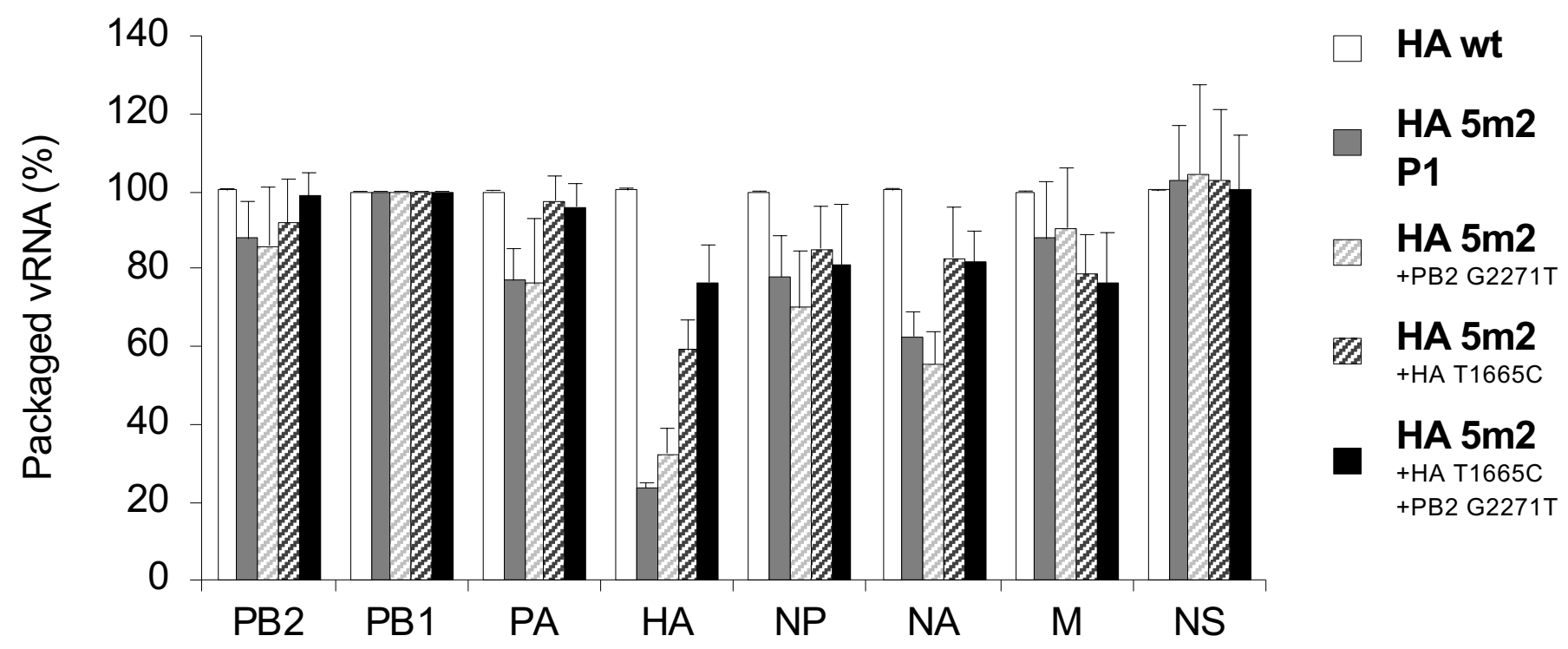

Fig 3. Packaging of individual vRNA segments into progeny viral particles. The amount of vRNA extracted from purified virus particles was quantified by RT-qPCR. All vRNAs were normalized to the amount of PB1 VRNA and to the average of that contained in the wild-type virus. Data represent the mean $\pm S D$ from two independent experiments each conducted in triplicate. (A) The panel shows the relative amounts of eight vRNA from the wild-type virus, HA 5m2 P10 virus, and HA 5m2 P1 virus. (B) The panel shows the relative amounts of eight vRNA from the wild-type virus and mutant $\mathrm{HA} 5 \mathrm{~m} 2$ viruses. 
A. perpetuity. It is made available under aCC-BY-NC-ND 4.0 International license.

\section{HA wt}
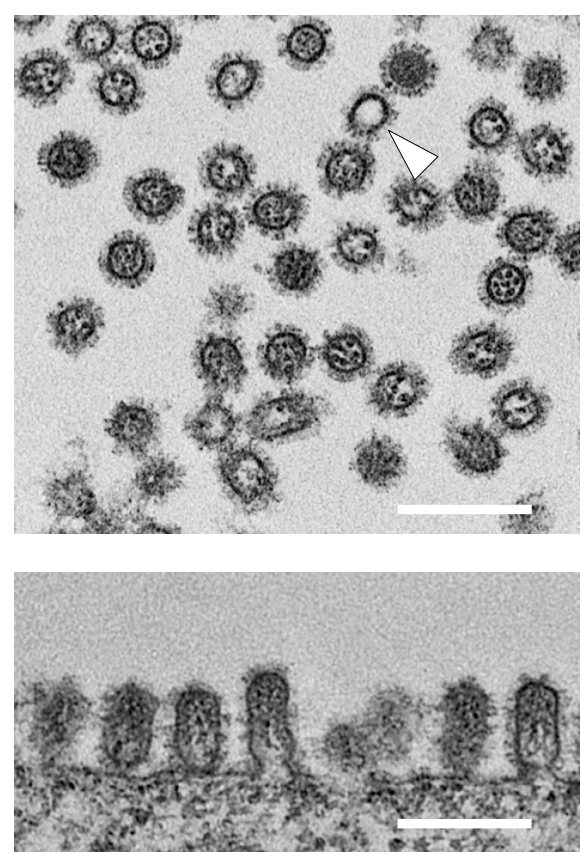

B.
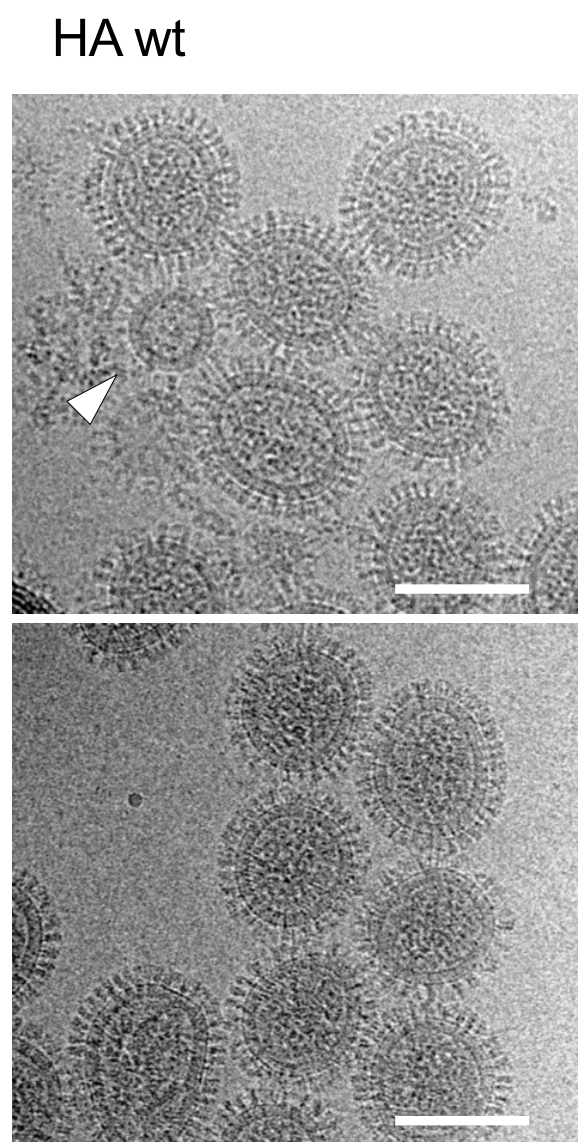

HA 5m2 P1
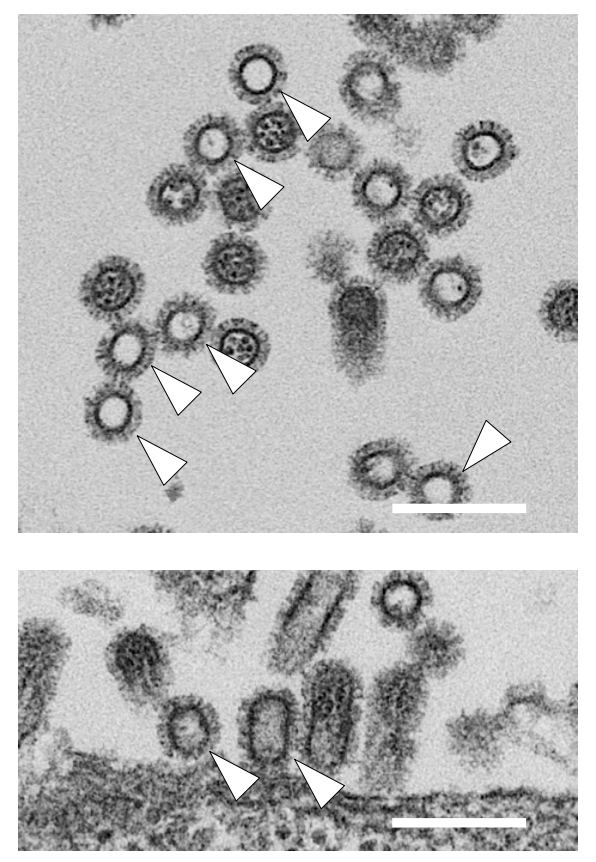

HA 5m2 P10
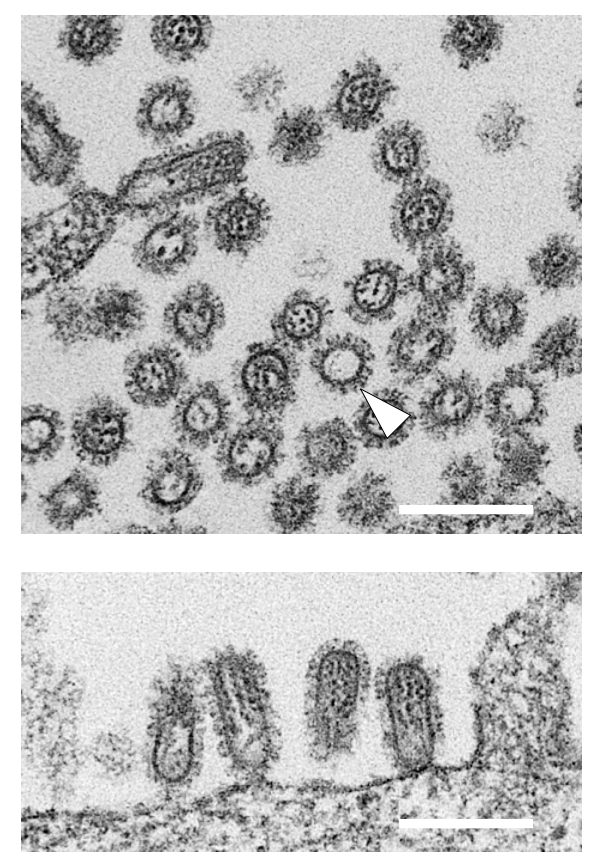

HA $5 m 2 \mathrm{P} 10$
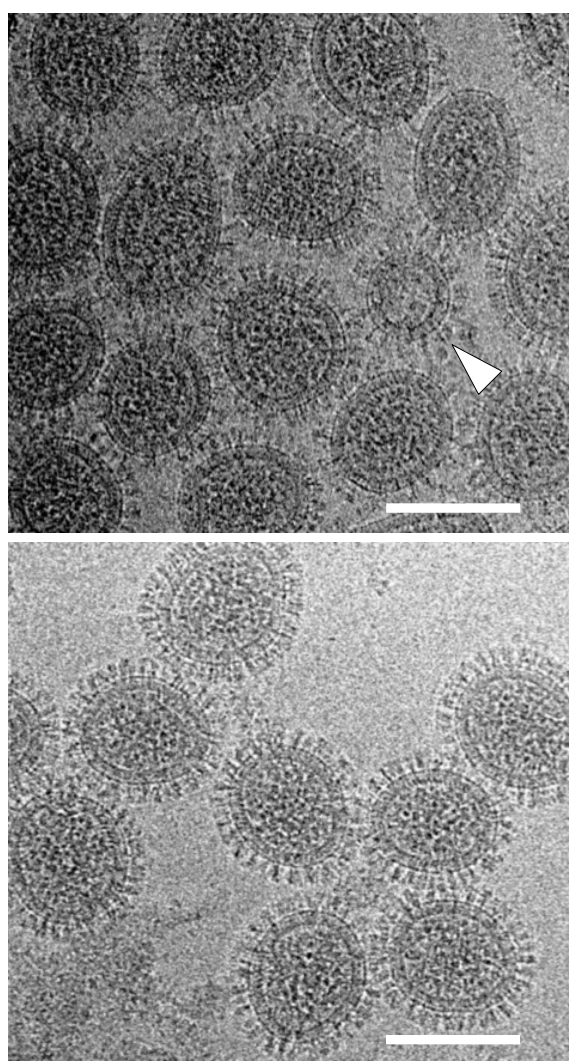

Fig 4. Morphology of HA $5 \mathrm{~m} 2 \mathrm{P1}, \mathrm{HA5m} 2 \mathrm{P} 10$, and wild-type viruses. (A) Ultrathin sections of viral particles budding from infected MDCK cells were observed using transverse section (upper side) and longitudinal section (lower side). Empty particles are indicated by arrowheads. Bars, $200 \mathrm{~nm}$. (B) Purified virus particles were observed by cryoTEM. Empty particles are indicated by arrowheads. Bars, $100 \mathrm{~nm}$. 
A.

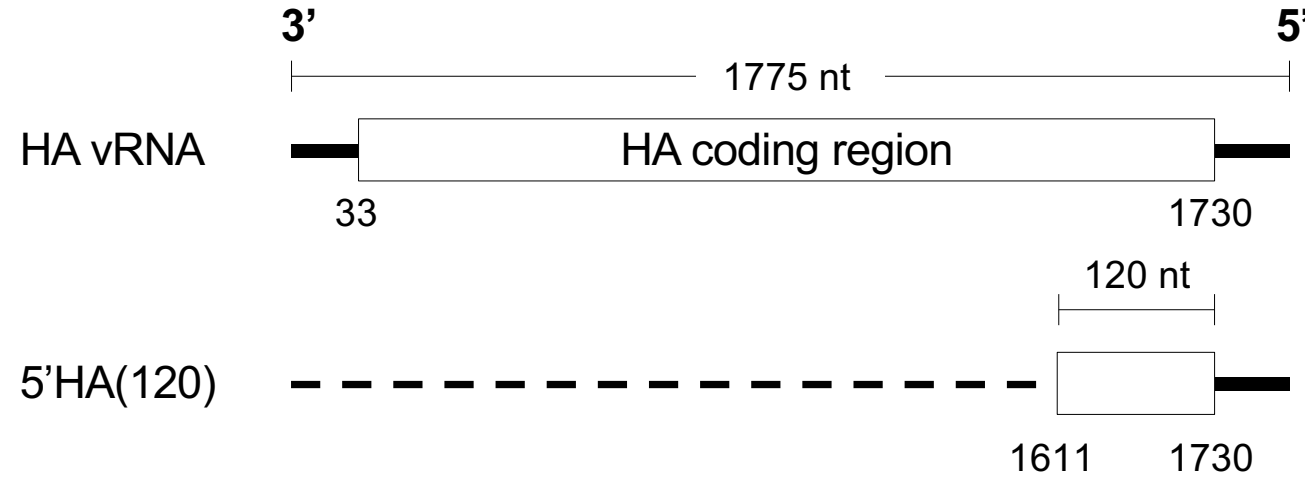

3'

PB2 vRNA

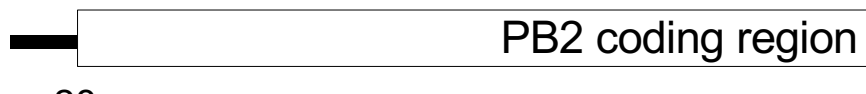

28

2307

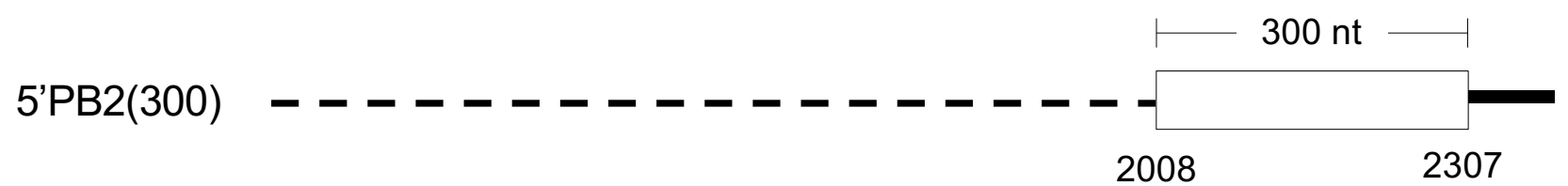

B.

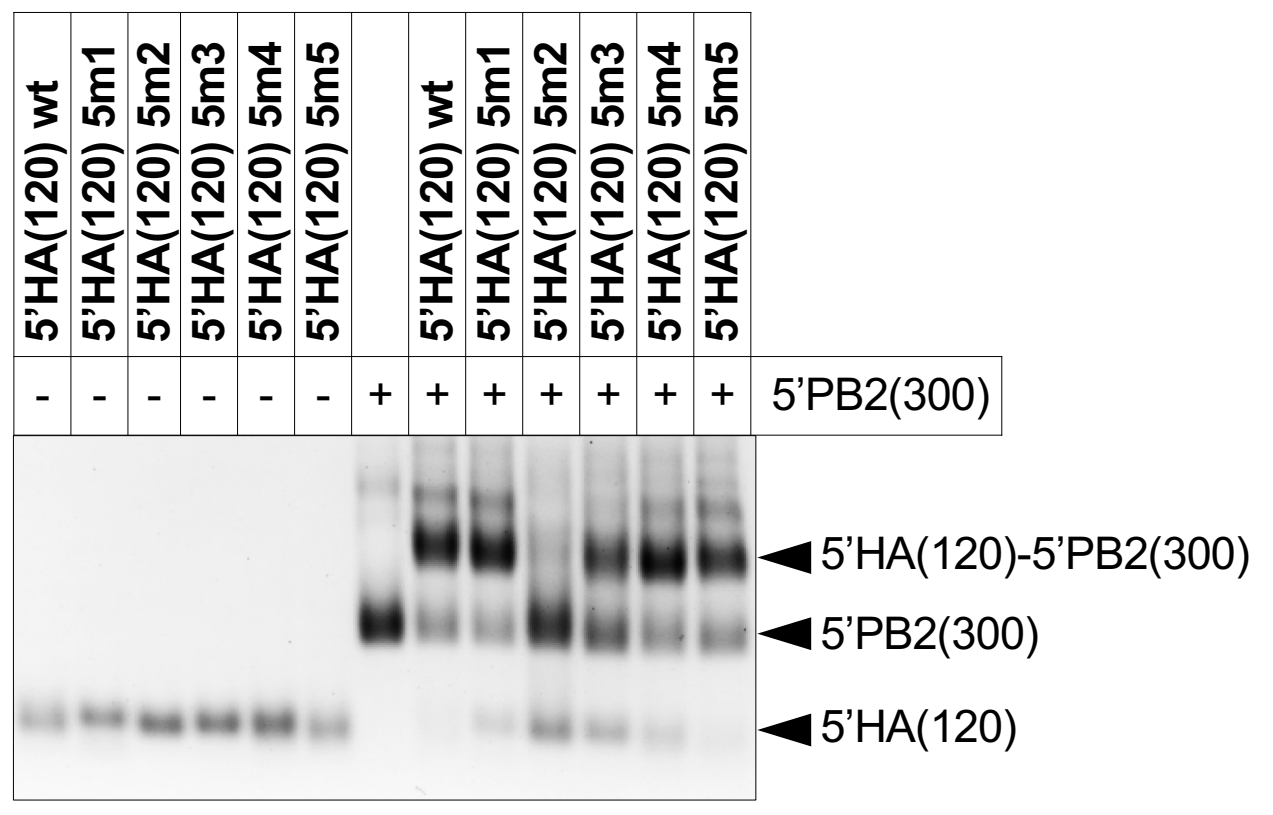

C.

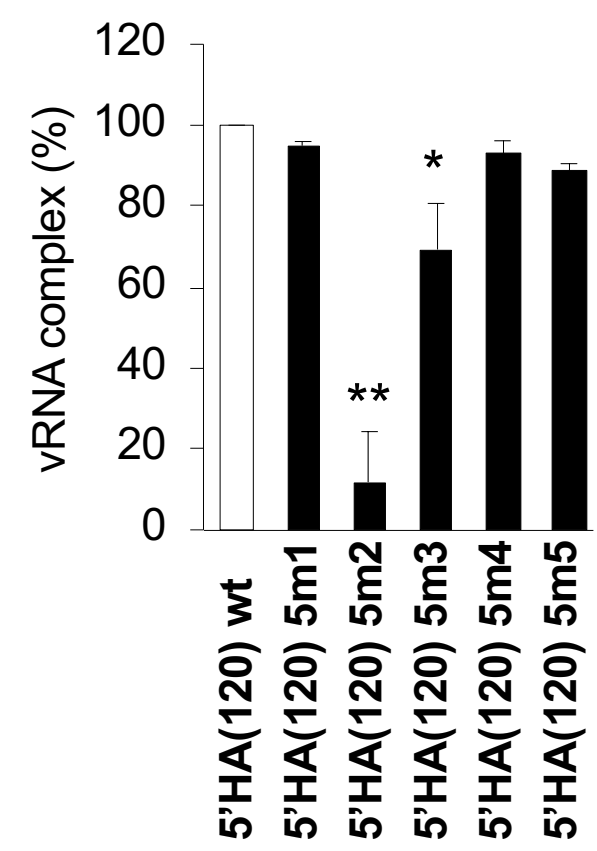

Fig 5. Gel shift assay using 5' end sequences of HA and PB2 vRNAs. (A) Schematic representation of $5^{\prime} \mathrm{HA}(120)$ and $5^{\prime} \mathrm{PB} 2(300)$ vRNAs. The solid line represents the noncoding regions of VRNAs at the $3^{\prime}$ and $5^{\prime}$ ends. The white box represents the coding regions of the HA or PB2 proteins. The dashed line represents the deleted regions. $5^{\prime} \mathrm{HA}(120)$ and 5'PB2(300) contain 120 or 300 nucleotides in the coding and noncoding regions at their $5^{\prime}$ ends, respectively. (B) The effect of silent mutations in $5^{\prime} H A(120)$ vRNA on binding to 5'PB2(300) vRNA. 5'PB2(300) vRNA was incubated with wild-type and mutated $5^{\prime} H A(120)$ vRNAs as indicated at the top of the gel image. Individual vRNA bands and vRNA complexes are indicated on the right. (C) Quantification of $5^{\prime} \mathrm{HA}(120)-5^{\prime}$

PB2(300) complexes for each lane. The relative band intensity of the complex is indicated in comparison to that of the wild-type. The data represent the mean $\pm S D(n=3)$. Dunnett's test; ${ }^{*} \mathrm{P}<0.01 ;{ }^{* *} \mathrm{P}<0.001$. 